\title{
Book Trailer as an Innovative Technology for the Formation of Students' Educational Independence During the COVID-19 Coronavirus Pandemic
}

\author{
Ponomareva L.I. ${ }^{1, *}$ Blyasova I. Yu. ${ }^{1}$ Novikov K.A. ${ }^{2}$ \\ Dubskich T.M. ${ }^{2}$ Achmetova K. S. ${ }^{2}$ \\ ${ }^{1}$ Shadrinsk State Pedagogical University, Shadrinsk, Russia \\ ${ }^{2}$ Chelyabinsk State Institute of Culture, Chelyabinsk, Russia \\ ${ }^{*}$ Corresponding author.Email:1dm1020@mail.ru
}

\begin{abstract}
The article analyzes the relevance of using one of the most interesting innovative technologies - the book trailer in the educational process of the university. The analysis of research in the field of booktrailer application shows that its correct application contributes to the formation of educational independence among students of higher educational institutions, the special relevance of which is determined by the conditions of isolation during the coronavirus pandemic. Requirements for university graduates are growing year by year, so a modern graduate is required to develop intellectual, communicative, informational and regulatory competencies, which are revealed through mobility, the ability to solve non-standard tasks, continuous selfimprovement, and focus on acquiring new knowledge. However, the social demand is not limited to the formation of these competencies during the training of students at the university. The main condition for studying at the University is the integrity (continuity) of the educational process, provided by the standard of higher education. The absence of direct contact between a teacher and a student during the COVID-19 pandemic does not exempt all participants in the educational process from acquiring the necessary competencies for learning material. The main advantage of the competencies formed at the university is the possibility of their use after graduation in professional and other spheres of life. The existing system of education continuity actualizes the feasibility of finding optimal conditions for the implementation of the idea of lifelong learning. In accordance with the European Lifelong Learning Initiative, education is a permanent process, which is not just a basis, but also an incentive for the development and improvement of the personality, capable of independently gaining knowledge, mastering values, and forming the necessary skills. This article presents the main features of the book trailer technology; the features of the use of this innovative technology in the activities of the university are disclosed during the transition to remote training; the application of this technology on the basis of empirical verification of its results on a sample of university students is justified. It was revealed that after using this technology in the framework of the school year, changes occur in the motivational, cognitive and behavioral components of students' educational independence. The materials of the article are of practice-oriented nature and are of practical value for persons involved in the training of specialists in the system of higher pedagogical education.
\end{abstract}

Keywords: educational independence, innovative technologies, book trailer, students' potential realization,

COVID-19 coronavirus pandemic

\section{INTRODUCTION}

The relevance of the study is due to the need to study and implement innovative technologies and mechanisms for the formation of personal characteristics, during the transition to distance learning in connection with the statement of the Director General of the world health organization, Tedros Gebreyesus, declaring coronavirus a pandemic (a Pandemic is the spread of a new disease on a global scale), and of a citizen that meets the requirements of modern Russian society [14]. The concept for the development of continuing education of the population living in the territory of the Russian Federation for the period up to 2025, in Section III, directly indicates the need for the following measures: "Improving educational technologies that provide citizens with free access to educational content, including learning technologies using mobile devices (clause 3.3); "Formation of social mechanisms providing stimulation of demand on the part 
of the adult population for lifelong learning" (Section 3.4) [7].

Compliance with these laws ensured a painless transition to distance learning in conditions of declared isolation during the coronavirus pandemic.

The well-established postulate of "education for life", in modern conditions, is no longer relevant, it is replaced by " lifelong learning." And this is not even a transition from one level of education to another (from preschool to primary, then to secondary education), which is necessary for socialization, education and the choice of the necessary profession [5]. Rather, it means that even getting a higher education (in the hierarchy of levels of the continuing education system higher education is the last level) does not give reason to stop the educational process., since a person holding a diploma of higher education will have to constantly improve his professional level (to undergo continuing education, professional retraining, etc.). Thus, the implementation of lifelong learning will be ensured by the ability of the individual to organize creative, independent activity, to search for the necessary information, as well as to manage his self-education. The effectiveness (or insufficiency) of preparation for this process was felt by all educational institutions during the transition to online in the context of the coronavirus pandemic. The highlighted priority of individual independence in the educational process of training specialists with higher education actualizes the problem of the formation of educational independence of students of Russian universities.

It should be noted that in psychological and pedagogical research, both domestic and foreign scientists, the theoretical prerequisites are laid in solving the problem of forming the educational independence of students in higher education, taking into account the modernization of the national education system of higher education.

The historical and logical review of psychological and pedagogical research convincingly proves that the urgency of the problem of the formation and development of students' independence does not wane, but it increases many times over. At different times this problem was addressed by such prominent scientists as: C. M. Abramova, M.A. Danilov, B.P. Esipov, I. Ya. Lerner, P.I. Pidkasisty, V.A. Shchedrin and others. T.A. Voronova, T.E. Klimova, G.N. Serikov and others devote special attention to finding ways of effective practices and organizing the process of students' independent work, both in the educational process and in unregulated activities, including other educational and cultural activities. In addition, we should note studies on the training of future teachers for self-education and reflection, the possibility of advanced training and retraining, the use of online (English online), offline (English offline), remote and a variety of case technologies that were studied by V.A. Adolph, A. M. Kovaleva, L.N. Pavlova, A. M. Treschev and others.

The analysis of the domestic educational methodology of training specialists of higher education, as well as the study of theoretical prerequisites and practical aspects of the formation of independence among students, allowed us to highlight the main contradiction: between the requirements laid down in legislative acts, as well as the growing need of society for a teacher of a "new formation" capable of implementing innovative technologies, an independent search for the necessary information, selfeducation and reflection throughout life, and insufficient a new awareness of the possibilities of the formed educational independence of students in a modern university.

In this regard, this article is aimed at considering the innovative technology of a book trailer as an optimal condition for the development of educational independence of students of a pedagogical university.

\section{METHODOLOGY AND METHODS}

The methodological basis of the problem of the formation of educational independence is a personality-oriented approach developed by E.V. Bondarevskaya, S.V. Kulnevich, V.N. Myasischev, K.K. Platonov, D.I. Feldstein and others. The theoretical basis of this study is the scientific research of prominent philosophers $F$. Nietzsche, V.Ya. Pilipovsky, E. Fromm and others; we should note the research of philosophers E.V. Andrienko, M.B. Boguslavsky, V.P. Zinchenko and others, about the personality as an independent subject, as well as the value development of reality; the theory of free education of K.N. Wentzel, J.-J. Russo, L.N. Tolstoy and others. In addition, the basis of the study we are considering is the philosophical and psychological-pedagogical thoughts of V.V. Ignatova, I.F. Isaev, S.I. Hessen, M.V. Clarin and others about self-realization, self-determination of students in the educational space of the university. Of particular interest are the teachings on understanding the essence of education as a self-governing system capable of solving the tasks of self-development and self-organization of the younger generation, set forth in the writings of V.A. Adolf, E.V. Ilyenkova, Yu.V. Senko, M.I. Shilova.

So, today the continuity of the modern education system is universally recognized. It determines both the need and the sufficiency of specially selected conditions for the implementation of the essential characteristics of education - its distribution, extension and continuity throughout the life of an individual. It is continuity that provides a person with the opportunity to comprehensively develop, form value orientations, competencies, abilities and skills that will be further used depending on the life situation that the individual will live. However, in the context of the declared COVID-19 pandemic, more than a million students were separated from their educational institutions. This forced the heads of institutions, teachers, students and their parents to quickly adapt to unusual conditions and look for new learning technologies.

In addition to obtaining the competencies necessary for professional activities the modern State educational standard of higher education is designed to solve the main goal - to prepare a student, a future graduate of the university for independent socialization for society and continuous self-education and self-development. 
In the Concept of the Federal Targeted Program for the Development of Education, the need to comply with the important principle of the successful organization of education - in any educational system, the equal responsibility of all subjects of the educational process for the results of educational activities must be respected [7]. At the same time, many scientists and practitioners, characterizing the modern system of Russian education, note the paradoxical situation that has developed in it: thus, "Education act of Russian Federation" defines the status of a student as a subject of educational activity, at the same time, higher education is built on logic informational and receptive learning, which considers the student as an object of educational activity, not responsible for the results obtained in the learning process.

The aforementioned actualizes the need to form educational independence skills.

Let us pass to the essential consideration of the category of "educational independence". It is accepted in science that any detailed study of an object (phenomenon, concept) begins with an appeal to philosophical sources. We adhere to this logic, and, we note that from a philosophical point of view, "education", as a concept, is considered in two ways. Firstly, as a "containing image", and secondly, as "creating your own image". As you can see, in each of these cases the key word is "image". Consequently, the essence of education, in philosophical terms, should be understood as a continuous, purposeful "ascent" of a person to a certain peak (in this consideration - to knowledge), the acquisition by a person of his own image, different from all others: "To educate a person is not just to convey to him a certain amount of knowledge, but also to reveal a certain image in him "[6].

In studies, one can often find an understanding of modern education, as a kind of shell "formation of the way of being", within this shell the image of a specific individual is born and develops. However, this is not an isolated shell; other spheres influence the development of education. So, all the changes taking place in the spheres of the development of society: economy, culture, politics, will inevitably affect education. V.A. Slastenin, G.I. Chizhakova in the concept of "education" take the following algorithmic steps: setting a goal, developing a model, phased follow-up with solutions to emerging problems, the formation of a new image of the subject based on individual needs and existing inclinations. Based on the selected algorithm, the authors substantiate the external and internal components in the structure of education [15]. A fairly widespread application in the history and philosophy of education is the concept of "personality education". It implies a lengthy process of individual human activity in finding, selecting and assimilating certain information, personal responsibility for the actions performed and the integration of acquired knowledge in various spheres of life, including professional. Such scientists as B.S. Gershunsky, N.D. Nikandrova, V.M. Rosina studied the process of personality formation. All of these scientists note the need to master the "basic" education. The acquisition of such a universal education will allow each person to independently, based on existing knowledge, carry out his professional activities and, if necessary, acquire new knowledge for professional growth. V.M. Rozinnotes that educated personis not so much a" knowing person ", it is a person prepared for life, guided by the complex problems of modern culture, able to comprehend its place in the world, able to bear responsibility for its actions, which will build itself in a certain sense [15]

The logic of our presentation of the problem allows us to consider the process of obtaining education not as an external component in relation to an individual, but, to a greater extent, as a result of the activity of a particular person, his work in the "internal plane". Consequently, the result of education should not be a set of knowledge and ideas that a person masters, but the integration of knowledge with the personal qualities of the individual.

Let us dwell on the definitive characterization of the problem of individual independence. In the encyclopedic dictionary on pedagogy, independence is interpreted as a personality trait that determines the individual's ability to consciously carry out his actions, in any circumstances to make his own decision, be responsible for his actions and the social role he has taken on, have a personal opinion [1, p. 255]. By pedagogical research, independence is commonly understood as the leading quality of personality. Independence can act in different forms: clearly formulate a goal, realize its significance for personal development, purposefully solve tasks, and solve them without any outside help, according to the plan and conscious actions. Most often, in pedagogical dictionaries and encyclopedias it is noted that the phenomenon of "self-sufficiency of personality" is formed simultaneously with such personality traits as initiative, endurance and self-control, that is, it is part of the volitional sphere.

Turning to the methodological characteristics of the concept under consideration, it should be noted that in philosophical dictionaries it is quite difficult to find a comprehensive understanding of the category of "independence", probably because it relates more to psychological and pedagogical research. Nevertheless, in the Modern Philosophical Dictionary we find the word "self", that is, "self" is a part of a series of complex words that mean directing (strengthening) on oneself, more often understood as actions that a person performs without assistance [6, pp. 758-759]. Numerous definitions with the prefix self- (self-education, self-development, self-control, etc.) give special meaning to words and fill their content with their own logic of development. This logic is clearly traced in the psychological understanding of the phenomenon of independence. So, different areas of psychological science have given rise to scientific schools studying independence as:

- personality trait (L.S. Vygotsky);

- subjective experience and activity (A.K. Osnitsky);

- quality of personality (S.L. Rubinstein);

- the ability of the individual (K.K. Platonov);

- a model of human behavior (A. Reber).

Following the determinants discussed above, which at first glance look at independence in different ways, we should single out a common ground for all of the above - 
independence in the personal plan is an internal factor of the personality and, of course, prevails over external circumstances.

Various aspects of the organization of self-educational activities of students, the development of skills for independent search, processing and broadcasting of received information, traditionally receive a lot of attention from both domestic and foreign scientists.

The historical and logical analysis of the study of the problem of students' independence is reflected in the writings of famous foreign masters of pedagogy such as F.A. Dysterweg, J.A., Comenius, J. Zh. Russo, I.G. Pestalozzi and others. Paying special attention to the selection of certain conditions for the development of independence in various types of activities of the child, teachers of the past assigned a special role to the development of independence in education.

Y.A. Comenius, in the classic work "The Great Didactics", put forward the principle of independence as the most important principle of teaching. The scientist assigned him a special role in the child's knowledge of the world [7, p. 274].

At the beginning of the nineteenth century, a German teacher and public figure - F.A. Disterweg consider upbringing as the development of independence in the direct activities of children. It was he who proclaimed the slogan, which still lives today - "to educate is to encourage". In his work, he wrote that "... development and education cannot be given to any person. Anyone who wants to learn something must achieve this by his own activity, by his own forces, by his own tension. From the outside, he can only receive an impulse "[4, p. 118].

According to the Professional Standard, each teacher must have intellectual and pedagogical, communicative, informational and regulatory competence, which is revealed through mobility, the ability to solve nonstandard tasks, continuous self-improvement, and the focus on acquiring new knowledge.

All of the listed competencies, in our opinion, cannot fully function without such an important educational action of a teacher as educational independence manifested in the initiative, personal interest in education, knowledge of the ways of organizing educational activities, and the desire for self-education. Moreover, this action is formed throughout the entire professional formation of the teacher, starting from the student's "bench". However, our study showed that future teachers have a low (reproductive) level of development of this action. This trend served as the reason for conducting experimental work on the establishment of educational independence of students in a pedagogical university.

At the starting stage of the experimental part of the study, the state of the formation of the educational independence of full-time students of 2-3 courses of the pedagogical faculty of the Shadrinsk State Pedagogical University in the amount of 180 people was studied. To determine the level of formation of the educational independence of students at the university, we took into account the specifics of the phenomenon of "educational independence", as well as the specifics of the organization of the educational process of a pedagogical university. In addition, the requirements of the State educational standard of higher education on the quality of graduate training were also taken into account when conducting experimental work on the formation of educational independence among university students. Firstly, we have identified the requirements indicated in the qualification profile of the graduate. They are arranged according to the hierarchy:

- A conscious choice to master educational programs;

- free use by students of modern technologies, methods and teaching aids;

- the active participation of students in scientific, educational activities;

- the ability to freely search for information, including Internet resources;

- creative activity and self-improvement in a professional way.

Fulfillment of these requirements presupposes students to have a high level of educational independence.

The coronavirus pandemic has accelerated the transition of Russian education to radical changes in the use of Internet technologies. On March 30, Russian Prime Minister Mikhail Mishustin issued a statement on the introduction of a self-isolation regime, and on March 31, 26 regions introduced this regime in their districts. Since then, education has switched to a new mode of operation online. The higher school of Economics conducted a survey of about 8,000 people from different regions of our country, who unanimously indicated that during the period of self-isolation, they had to rebuild their usual lifestyle, as well as spend more time preparing for homework.

Before embarking on the experimental part of our study, we analyzed the studies available in this area, which already contain some experimental data. For example, research by I.P. Herzik, N.F. Panikarova, A.A. Omarova, E.A. Taranchuk and others, indicate that some of the students of universities (regardless of specialized training), mainly have analytical skills [12], [13], [18]. Starting from the second year, the majority of students are responsible for planning their educational activities. This category of students is actively involved in cultural events, sports competitions, volunteer movements. Students take the initiative in self-organizing social events. The research results show that students are able to understand the personal importance of getting an education, are aware of their own abilities and are focused on revealing their talents, are critical of their personal needs and those of their peers, and highlight self-realization and selfexpression in the hierarchy of needs. In our opinion, it is precisely the features of students that we examined above that are important prerequisites for educational independence formed in the learning process.

In addition to the distinguished features, we took into account the generally recognized in science, in particular in humanistic psychology, point of view that only an independent person is able to consciously control his actions. This point of view is based on D.A. Leontiev, who introduce a new category of "semantic logic of behavior" 
into psychology. Today, this category has a persistent set of personal values, and, no less important, the needs of the individual. Based on the context of the problem we are considering, it should be noted that it is values and needs that give meaning to all actions of the individual. Consequently, a person's desire for independent actions is nothing but the initial stage in the formation of educational independence. At the same time, the individual should be clearly aware of the importance of his own independence, and most importantly, this quality should be included in the structure of the value-semantic sphere of the individual [10].

In addition, when studying the educational independence of students of ShSPU, we also took into account the point of view of L.S. Vygotsky on the choice of the future path of life. From his research, we took out and took into account the idea that self-determination, both professionally and personally, should become for students the "semantic and motivational center that determines the level of their responsibility and consciousness in the learning process, which the future will affect the choice of life trajectory" [20].

Turning to the description of the practical part, we should summarize the study of the theoretical foundations of the basic categories of research: firstly, the formation of educational independence among students suggests that they have meaning life orientations; secondly, each individual has his own set of value and semantic orientations; thirdly, the manifestation of independence is impossible without awareness of the goal, as a fundamental aspect of the existence of the individual.

It was these findings that determined the choice of methodology for establishing the level of life orientation of students of 2-3 courses of the university. To this end, we have chosen the test "Meaning life orientations" by D.A. Leontiev.

Despite the fact that this technique is auxiliary to the determination of educational independence, it is it that allows one to identify such important components as life goals, meanings and needs of the younger generation.

The scales that the methodology contains have values that play a role in revealing the level of formation of educational independence. Let us imagine these scales: 1) the subscale "Goals", based on the name, comes the understanding that it displays the presence of a life goal; 2) subscale "Process" - means the perception of what is happening around person's life, in other words satisfaction in the present; 3) subscale "Result" - shows satisfaction with the achieved life results; 4) the subscale "Locus of control - I" means taking personal responsibility for what is happening; 5) the subscale "Locus of control life" helps to understand how a person controls his life. Below, in Figure 1, we present the students' choice of important life orientations for determining the formation of educational independence.

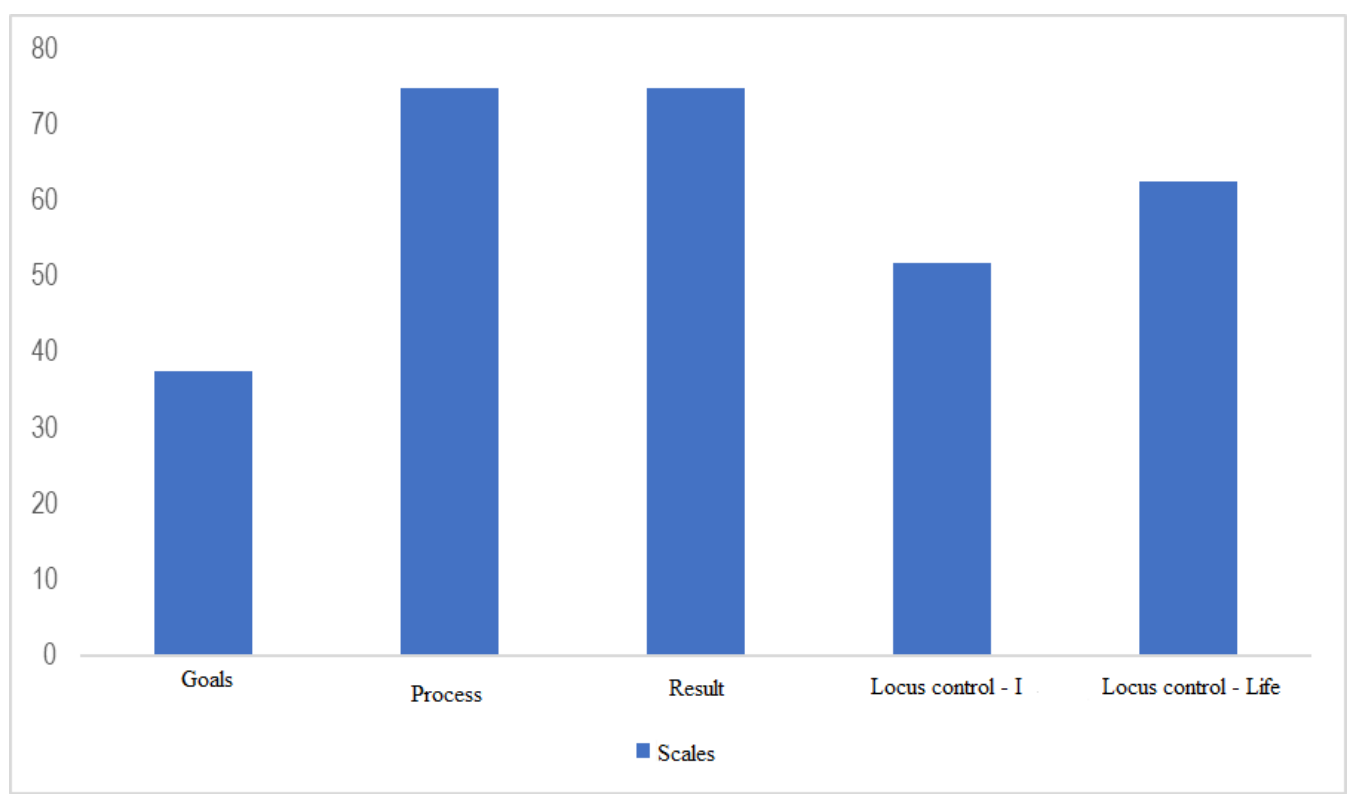

Figure 1 Scale of choice of meaning-life orientations (of the total number of students \%)

After analyzing the data obtained on the test, we found that the average values of the scales for students of ShSPU, albeit slightly, exceed the generally accepted normative values of this test. However, it should be noted that according to existing scales, deviations from the norm fluctuate within acceptable normative values. The analysis showed that the majority of second and third year students $(75 \%)$ tend to perceive their life as emotionally rich, interesting and full of meaning, which means a high deviation from the norm on the "Process" scale. In addition, these students are satisfied with the lived part of their lives and the results achieved (value on the "Result" scale). $62.5 \%$ of students are convinced that they "keep their eye on the ball", that is, they completely control their life. Students of this group said that, as a rule, they singlehandedly make decisions and can bring them to life (high 
deviation on the scale "LC - life"). The results of the following scale "LK - I" demonstrate that $51.8 \%$ of students have ideas about themselves as a whole person. These students position themselves as strong people who are able to independently build their lives on the basis of their near and long-term goals (average deviation on a scale of "LK - I"). And only a few university students $(37.5 \%)$ indicated the presence in their lives of clear values and conscious goals that give meaningfulness and orientation to the life activity (low deviation on the "Goals" scale).

The components of educational independence that we identified in the theoretical analysis of the problem under consideration in this article - the cognitive, motivational, and activity components - formed the basis for studying the levels of this type of independence. Since the formation of these components is an indicator of the educational independence of students in universities. This provision has determined the need for the formation of educational independence in our experimental work strictly on these components. In the following figures, the formation (by levels) of the educational independence of second and third year students of the university in terms of the selected components is successively presented.

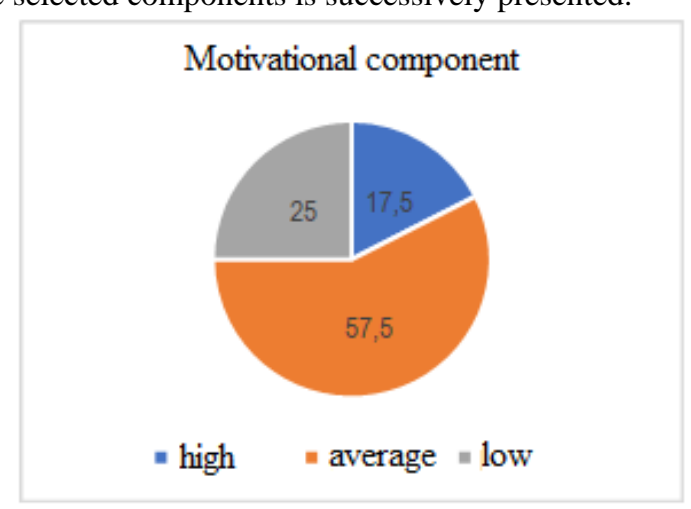

Figure 2 Levels of formation of the motivational component of educational independence

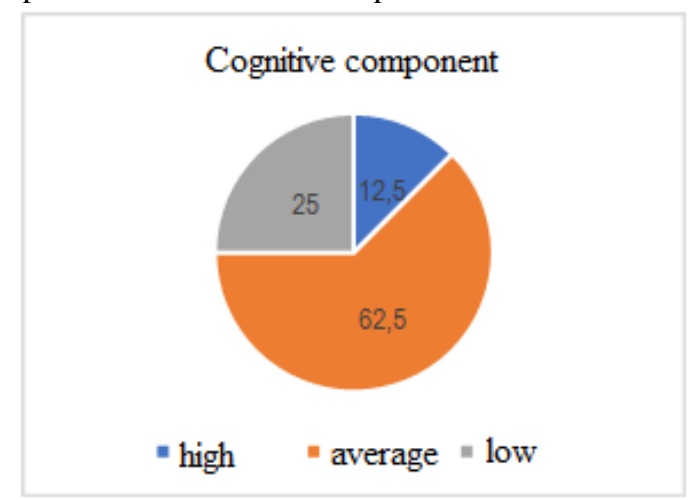

Figure 3 The levels of formation of the cognitive component of educational independence

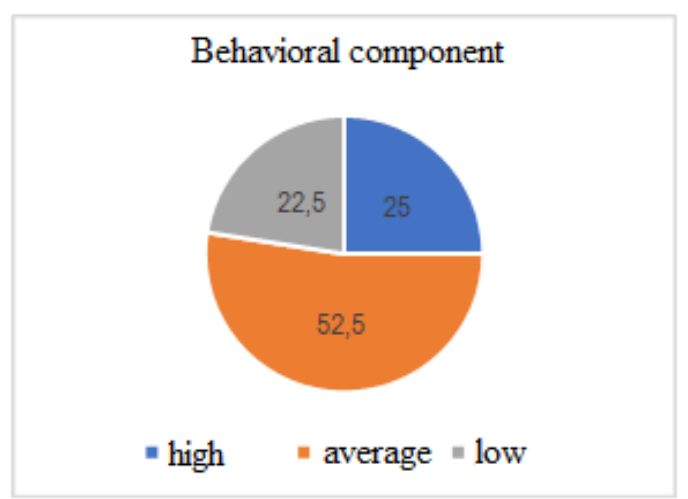

Figure 4 Levels of formation of the behavioral component of educational independence

Studying the traditional organization of psychological and pedagogical disciplines at the university, as well as mastering the content of these subjects by students, allowed us to identify the following features: a sufficient number of students $(62.5 \%)$ do not seek to consciously master the content of the discipline of the curriculum. Oddly enough, this group of students does not see the dependence of the assimilation of subject content on the manifestation of their own independent educational activity. This group of students clearly shows a line of not independent choice of the specialty they receive (parents order, students didn't manage with the competition for the chosen specialty, did not have to choose specialty, because the USE scores are low, etc.). $37.5 \%$ of boys and girls show an unstable positive attitude towards independent education. They agree to study, but believe that their level of knowledge depends on the qualifications of university teachers. Of course, the assimilation of certain competencies is the prerogative of university teachers, but we can not ignore the hard work of students and their desire to independently find the necessary information. A significant part of the younger generation $(56.8 \%)$ frankly admit: they cannot properly organize their independent work related to the study of lectures and preparation for practical exercises, although they have a desire to learn how to do this. Almost half of the students - $47.5 \%$, in general, are neither able to manage nor organize their own independent activities. At the same time, almost all students of this group prefer leisure activities like watching television, and spending time on social networks to independent educational activities.

Summarizing the foregoing, we hypothesized that for the effective assimilation of the subject content of the course of the psychological and pedagogical cycle of the curriculum for university students, it is necessary to form educational independence as a personal quality. In addition, this will improve the systematic self-directed educational activity on the initiative of the students with their internal motivation. Self-isolation conditions in the context of a coronavirus pandemic have given this task a special urgency.

For this purpose, we have chosen such an innovative technology as a book trailer. 
The concept of "book trailer" appeared and began to be used for educational purposes relatively recently. Initially, this concept was understood as a mounted slide show of images, illustrations of a work of art, which the author would like to tell his readers, a form of advertising of a published novel, story or other genre of a book. Although the first book trailer was created in 1986, this type of advertising gained particular popularity after 2003, which was associated with the holding of a book fair in Louisiana. If we talk about the use of booktrailers in Russian education, it became popular by the 2010s (studies by Yu.V. Shcherbinina, N.V. Shevtsova and other authors). Then, for the first time, studies appear that prove the effectiveness of using this form no longer as exclusively marketing, necessary for the sale of a particular publication, but precisely as an innovative form of training that can develop the reader's interest in students [7].

In this regard, the book trailer is already understood as "the technology of literary education ... a special type of visual interpretation of a literary text using multimedia in order to attract reader's attention" [11]. The interest in studying the influence of book trailers on the development of students' personalities was reflected in the works devoted to this topic at all levels of education (preschool education - T.V. Banina; secondary education - M.V. Babkina, E.A. Baranova, N.V. Volkova, O. A. Mokhun, N.A.Kolodina, higher education - N.I. Nikonova, V.V. Terentyev) [9]. However, most researchers focus on the development of interest in reading through the introduction of book trailers, while we believe that this form of work also contributes to the formation of educational independence. The essence of the technology we are considering is as follows. In each study group, we identified 3 working groups, including approximately the same number of participants. The roles of a "director," coordinating the work of the entire group, a "screenwriter," responsible for the plot of the book trailer, and an "operator" mounting the book trailer, were selected and distributed among the participants in the groups. Each group discussed and selected a study topic that was interesting to everyone. Study group were talking in the chat yourself. At the first stage, teacher and students discussed the methodology for using this form of work, the basic rules and requirements for book trailers. Ready-made book trailers of teachers, senior students, professional book trailers of publishing houses were considered as examples. Students studied features of working with book trailers and methods of their installation. So, there are several ways to visually present the content of the read material: game (mini-scenes), nongame (slide shows with illustrations, sound, etc.), animated (using animated tools), etc. [19]. Because of their capabilities, students were offered a non-gaming way to create a book trailer, because before that they had no installation experience.

At the second stage, each group worked independently, participants selected material, mounted, voiced. The main requirement was a full and in-depth study of the selected topic.
When choosing and discussing the topics of future booktrailers, students were interested in their activities, they developed the ability to set a goal, analyze, take initiative in solving. This stage involved work on previously discussed topics (selected tasks) independently. So, students selected material, mounted, voiced their text. In this regard, book trailers prepared by students related to the search for historical facts and events to present a historical and logical analysis of the development of a certain scientific idea, are interesting.

Subsequently, during the work on the book trailer, the students mastered the skills to optimize their own educational activities, independently search and select the necessary information, provide it in a non-standard form, without ready-made templates. Since all groups worked under the close attention of the teacher, we noted the continuous growth of students ' independence in the process of working on the booktrailer.

At the final stage, the presentation of the finished product allowed students to reflect on their and other works, and contributed to the development of communication, presentation and evaluation skills. The final stage included the demonstration and discussion of book trailers, their advantages and disadvantages; the best works were posted on the Youtube channel and appreciated by other Internet users. During the implementation of the technology, it can be seen that each stage of work with the book trailer was aimed at the development of the educational action that we are studying.

Thus, work with the book trailer is one of the effective forms of using information and communication technologies in the formation of students' educational independence in conditions of self-isolation during the coronavirus pandemic. In the course of the experimental work, the main types of book trailers were clarified in content: narrative, revealing the storyline; atmospheric, the purpose of which is to convey moods and emotions; conceptual, affecting the ideological essence of the proposed material.

\section{RESULTS AND DISCUSSION}

When choosing and discussing the topics of future booktrailers, students were interested in their activities, they developed the ability to set a goal, analyze, take initiative in solving.

Subsequently, directly during the work on the book trailer, students mastered the skills to optimize their own educational activities, independently search and select the necessary information, provide it in a non-standard way.

The innovative technology that we introduced - the use of the booktrailer in the educational process has shown its effectiveness in establishing the educational independence of students. This is also confirmed by the results obtained during the experimental work.

As already mentioned above, when analyzing the theoretical provisions of educational independence at the starting (ascertaining) stage of the study, we identified the following components: 
Motivational component. Only $17.5 \%$ of students revealed a high level of formation of this component of educational independence (at the stage of a stating experiment). They showed a highly developed need to realize their potential in the development and presentation of material in the process of preparing the tasks set by the teacher, the desire to learn new technologies, the willingness to improve themselves in a professional and personal way; marked a positive emotional attitude. Low levels were found in $25 \%$ of students. These students showed either unwillingness to participate in the experiment, or doubts about the appropriateness of using new technologies. They did not show initiative in educational activities and could not independently solve the tasks set by the teacher; emotional mood is either negative or neutral. They are characterized by a lack of desire to work independently on the solution of educational and professional problems, do not seek to acquire new knowledge, are not ready for intellectual stress. Most students (57.5\%) have an average level of development of the motivational component. They do not experience negative emotions when implementing new technologies, however, they prefer not to show initiative in their work, they are more likely to act according to a given pattern, the changes cause suspicion, the manifestation of independence in the performance of a learning task is insignificant. They are included in the work with external motivation on the part of the teacher or classmates.

Cognitive component. $12.5 \%$ of students showed a high level of formation of this component. They have ideas about the current state of modernization processes in education, about their own capabilities, as well as technologies that allow achieving better results in various types of activities. $62.5 \%$ of students have an average level of cognitive component formation. In general, they are guided by the peculiarities of their own potential, but they hardly distinguish the possibilities of further development, both personally and professionally, rarely take responsibility for making decisions. They included in the use of innovative technologies under the guidance of a teacher. $25 \%$ of students have low indicators: they can not conduct self-analysis of their personality, assess the degree of formation of moral, legal, civic culture, find it difficult to independently select topics for developing homework. Teachers note a low level of the knowledge component of the professional competencies of students in this category. Behavioral component. High rates of this component were found only in $25 \%$ of students. This is manifested in active participation in educational activities, the ability to organize and conduct various presentations at a good level, the willingness to learn new things, to participate in the implementation of various technologies of the pedagogical process. The average level is observed in $52.5 \%$ of respondents. They have a readiness for changes, participation in innovation, but lack experience and practical skills to realize their potential in various kinds of activities. A low level of development of this component was detected in 22.5\%; these students do not show initiative and independence in the search for information for homework, are limited to attending classes; a passive position is noted. A student with an unformed subjective position cannot be an active, goal-oriented and responsible citizen of the country.

The results of the primary diagnosis showed the need to use the technology of the book trailer in order to develop the educational independence of students. Due to the students' internal readiness for changes, we considered it necessary to introduce this technology into the educational process to create the conditions in which each student will be able to realize his own abilities and manifestations of independence.

The results of the diagnosisare presented in table 1 .

Table 1 Evaluating the effectiveness of the results

\begin{tabular}{|l|c|c|}
\hline $\begin{array}{c}\text { Component of } \\
\text { activity }\end{array}$ & $\begin{array}{c}\text { Primary } \\
\text { diagnosis }\end{array}$ & $\begin{array}{c}\text { Final } \\
\text { diagnosis }\end{array}$ \\
\hline \multicolumn{3}{|c|}{ Motivational component } \\
\hline high level Cognitive component \\
\hline average level & 17,5 & 25 \\
\hline low level & 57,5 & 62,5 \\
\hline \multicolumn{3}{|c|}{12,5} \\
\hline high level & 62,5 & 37,5 \\
\hline average level & 25 & 55,7 \\
\hline low level Behavioral component \\
\hline \multicolumn{3}{|c|}{25} \\
\hline high level & 52,5 & 35 \\
\hline average level & 22,5 & 58,2 \\
\hline low level & 6,8 \\
\hline
\end{tabular}

\section{CONCLUSION}

The final diagnosis showed an increase in indicators for all components of student activity. Thus, the indicators of the motivational component of a high level increased by $7.5 \%$, the average - by $5 \%$, the low level of the motivational component decreased by $12.5 \%$, it indicates positive changes in the students' attitude to their professional future and increased educational independence.

The most significant changes have occurred in the cognitive component. A high level was found in $37.5 \%$ of students in this group. After the implementation of the booktrailer technology, an increase in the level of students' knowledge was recorded.

It should be noted that positive changes have occurred in the behavioral component. This suggests that students not only show educational independence, but also through the developed book trailers begin to realize the goals of professional development, which is impossible without personal changes. The data of the expert assessment of teachers testifies to the changes that students have had during the academic year: increased activity, independence, responsibility, level of general culture, academic performance.

Thus, summing up the results of our study, it can be argued that the booktrailer technology is an effective means of forming students 'educational independence, as well as a condition for developing students' personal characteristics, based on the requirements of modern Russian society. The pedagogical activity of the university 
allows us to realize the full potential of this technology with a systematic and focused work in the context of a coronavirus pandemic.

\section{REFERENCES}

[1] B.M. Bim-Bad, Pedagogical Encyclopedic Dictionary, Moscow, 2002.

[2] V.D. Chernyak, M.A. Chernyak, Book Trailer, Mass literature in concepts and terms, Moscow, Flinta, 2018.

[3] V.V. Danilova, S.L. Suvorova, I.Y. Blyasova, Participative Management of Project and Research Activities in the educational Collage Environment, Espacios, 2018.

[4] A. Disterveg, Selected pedagogical essays, Moscow: Uchpedgiz, 1956.

[5] The Federal Law dated 29.12.2012 N 273-FZ "Education act of the Russian Federation", Electronic resource.

[6] V.E. Kemerov, Modern philosophical dictionary, Minsk, Panprint, 1998.

[7] Ya.A. Komenskij, The Great Didactics, Moscow, Pedagogika, 1982.

[8] The concept of development of continuing education of adults in the Russian Federation for the period until 2025, Electronic resource, 2015.

[9] K.S. Lebedeva, Technology of formation of educational independence for future teachers, VestnikTGPU (TSPU Bulletin), 2015, no.12, pp.42-47.

[10] D.A. Leont'ev, Test of meaning-life orientations, Moscow, Smysl, 1992.

[11] N.I. Nikonova, V.V. Terent'eva, Book trailer as a means of stimulating student interest, Azimut Scientific Research, pedagogy and psychology, 2019, vol. 8, no. 3(28).

[12] A.A. Omarova, The development of a tolerant consciousness of youth on humanistic values in the cultural and educational space of a multinational region. Extended Abstract of D.Sc. Thesis, 2016, p.24.

[13] N.F. Panikarova, E.A. Taranchuk, I.P. Gercik, Formation and development of educational independence and educational autonomy of students of a non-linguistic university by means of the electronic training course of the discipline "English", Distance and virtual learning, 2011, no.12. pp. 85-97.

[14] L.I. Ponomareva, Innovative technologies in working with children as a condition for the quality functioning of DOO, Scientific journal, Yalta, 2017, no. 57, part 3, pp.156-162.
[15] V.M. Rozin, Personality and its study, Moscow, Editorial URSS, 2004.

[16] V.A. Slastenin, G.I. Chizhova, Introduction to pedagogical axiology, Moscow, Publishing Center "Academy", 2003.

[17] O.P. Suharinova, Educational independence of the subject of open education, Discussion, 2016, no. 8 (71), pp.121-125.

[18] E.A. Taranchuk, Organizational and pedagogical conditions for the formation of educational independence of students of a pedagogical university. Extended Abstract of D.Sc. Thesis, Krasnoyarsk, 2008, P. 212.

[19] E.I. Tarasova, An individually-oriented system of preparing a future technology teacher for teaching younger students, Extended Abstract of D.Sc. Thesis, Bryansk, 2004, P.224.

[20] L.S. Vygotskij, Pedagogical Psychology, Moscow, Pedagogika, 1991. 